\title{
Modulação Espacial para Sistemas de Comunicação MIMO
}

\section{Spatial Modulation for MIMO Communication Systems}

\author{
Reginaldo Nunes de Souza ${ }^{1}$; Taufik Abrão ${ }^{2}$
}

\section{Resumo}

Este trabalho faz uma revisão dos principais esquemas de modulação espacial para sistemas de comunicação sem fio. São analisados o desempenho, a complexidade e o ganho de diversidade de três esquemas relativamente novos para sistemas com múltiplas antenas no transmissor e receptor (MIMO): a) esquema de transmissão por modulação espacial (SM); b) modulação por chaveamento espacial (SSK); c) modulação por chaveamento espacial generalizado (GSSK). Estes três esquemas oferecem baixa complexidade de implementação, maior taxa de dados quando comparado a sistemas com uma única antena no transmissor e no receptor (SISO), bem como oferecem flexibilidade de projeto, enquanto fazem uso das características aleatórias do canal de comunicação para transmissão de dados. O trabalho tem por objetivo explorar as principais características destes três esquemas e avaliar o compromisso desempenho-complexidade para determinar qual dos esquemas de modulação espacial apresenta maior potencialidade em termos de eficiência em potência e espectral.

Palavras-chave: Modulação espacial. MIMO. SIMO. GSSK. SSK. Detecção ML.

\begin{abstract}
This work provides a review on the main spatial modulation (SM) schemes, suitable to wireless communication systems. Performance, complexity and diversity gain of the three new spatial SM schemes suitable for multiple-input-multiple-output (MIMO) communication systems are analyzed: a) transmission scheme for spatial modulation (SM) scheme; b) space shift keying (SSK) scheme; c) generalized space shift keying (GSSK) scheme. These three schemes offer low complexity, higher data rate when compared to single-input-single-output (SISO) communication systems, as well as design flexibility, while exploits randomness characteristics of wireless communication channel for data transmission. The paper aims to explore the main features of those three SM schemes and to evaluate the inherent performance-complexity trade-off in order to determine which of those schemes results in a higher energy and spectral efficiencies.
\end{abstract}

Key words: Spatial modulation. MIMO. SIMO. GSSK. SSK. ML detection.

Aluno de mestrado do Departamento de Engenharia Elétrica, Universidade Estadual de Londrina.

Docente do Departamento de Engenharia Elétrica da Universidade Estadual de Londrina - DEEL-UEL; taufik@uel.br. 


\section{Introdução}

Nas últimas duas décadas, a comunicação sem fio tem testemunhado um significativo desenvolvimento com um persistente aumento na demanda de dados transmitidos por usuário, implicando na busca de sistemas com capacidade crescente de transmissão de dados (MESLEH, 2008). Entretanto, a disponibilidade de espectro de rádio de banda larga para serviços de dados de pacotes é limitada; dessa forma, é essencial o uso do espectro de forma mais eficiente. Nos últimos anos, sistemas MIMO têm evoluído consideravelmente. Sistemas MIMO utilizam o princípio da diversidade espacial no canal de rádio para aumentar efetivamente a taxa de dados, mantendo-se limitada a largura de banda.

Os sistemas MIMO podem ser caracterizados em três diferentes grupos. Em um primeiro grupo, a codificação espaço-temporal é capaz de produzir diversidade a partir de múltiplas (duas) antenas de transmissão, bem como gerar redundância temporal dos dados, permitindo uma decodificação confiável no receptor. Com isso, este grupo alcança ganho de diversidade, mas não alcança ganho na multiplexação, porém apresenta vantagens, tais como simplicidade de implementação com manutenção da taxa de codificação igual a um para o esquema de Alamouti (ALAMOUTI, 1998). O segundo grupo MIMO assume o conhecimento do canal no lado da transmissão e usa a decomposição por valores singulares (SVD - singular value decomposition) para obter ganho na capacidade (RALEIGH; CIOFFI, 1998). Finalmente, com o terceiro grupo, denominado multiplexação espacial, obtém-se aumento na taxa de dados, porém não necessariamente fornece diversidade na transmissão. Como exemplo deste grupo, destaca-se a técnica BLAST (Bell Labs Layered Space-Time) (FOSCHINI, 1996).

Entre estes três grupos, a técnica de multiplexação espacial torna-se uma escolha apropriada para implementações futuras devido à demanda crescente por elevadas taxas de dados, as quais podem ser atingidas facilmente com essa técnica (MESLEH, 2008). Entretanto, a técnica de multiplexação espacial possui sérias limitações, tais como alta interferência entre canais (ICI interchannel interference) no lado da recepção, propagação de erros e alta complexidade na detecção (GOLDSMITH, 2003).

Como alternativa a este cenário, recentemente Mesleh et al. (2006) propuseram a técnica de modulação espacial aplicado a canais MIMO sem fio (SM - spatial modulation). Trata-se de um esquema relativamente novo o qual explora o ganho de multiplexação espacial para sistemas de transmissão com múltiplas antenas, cujo objetivo é evitar as limitações supracitadas da multiplexação espacial. Na modulação espacial, um bloco de bits de informação é mapeado em um ponto da constelação no domínio do sinal, e um ponto da constelação no domínio espacial. Em cada instante de tempo somente uma antena de transmissão do conjunto será ativada, enquanto nas demais antenas não haverá transmissão de sinal. Isto permite ao esquema SM evitar inteiramente a ICI, não requerer sincronização entre as antenas transmissoras e usar somente uma conexão de rádio frequência. No esquema $\mathrm{SM}$, a posição de cada antena do conjunto de antenas transmissoras é usada como fonte de informação, ou seja, o índice da antena ativa mapeia parte dos bits a serem transmitidos. Esta característica permite ao esquema SM obter ganho de multiplexação em relação ao sistemas convencionais, com uma única antena de transmissão. Ademais, apesar de uma única antena ser ativada a cada instante, o SM também obtém throughput elevado. Na recepção, a combinação de máxima razão (MRRC - maximum receive ratio combining) é usada para identificar o número da antena de transmissão; em seguida, o símbolo transmitido é estimado. Estas duas etapas de estimação são usadas pelo demodulador espacial para recuperar o bloco de bits de informação transmitido.

Em (MESLEH; GANESAN; HAAS, 2007) são discutidos os efeitos de imperfeições no canal 
(desvanecimento Rice, correlação espacial e acoplamento mútuo entre antenas) sobre sistemas combinando OFDM (orthogonal frequency division multiplexing), SM e esquema BLAST vertical (WOLNIANSKY et al., 1998) (V-BLAST). Em comparação com o V-BLAST-OFDM, o esquema de transmissão SM-OFDM apresenta ganho de até $7 \mathrm{~dB}$ para a mesma taxa de dados. Mostra-se também que a modulação espacial é muito mais robusta à presença de imperfeições no canal quando comparado ao V-BLAST. Este desempenho deve-se à capacidade do esquema SM evitar interferência inter-portadora. Em (JEGANATHAN; GHRAYEB; SZCZECINSKI, 2008b) foi proposto um esquema de detecção ótima SM baseado no detector de máxima verossimilhança que identifica o índice da antena transmissora e o símbolo transmitido de forma conjunta. A detecção ótima apresenta melhores resultados que a detecção proposta anteriormente em (MESLEH et al., 2006), com ganho aproximado de $4 \mathrm{~dB}$. Também é mostrado que a modulação espacial com detector ótimo atinge um ganho na faixa de $3 \mathrm{~dB}$ sobre sistemas MIMO convencionais, como a técnica V-BLAST. O desempenho dos algoritmos de detecção MIMO baseado na busca em árvore segundo o princípio do raio ajustável da hiperesfera (SD - sphere decoding), aplicados aos sistemas SM, é analisado em (YOUNIS et al., 2011). Para uma mesma taxa de erro, o desempenho obtido pelo algoritmo SD-MIMO é equivalente ao apresentado pela detecção ML, porém com significativa redução na complexidade computacional quando a relação sinal-ruído não resultar demasiadamente pequena.

Um esquema de modulação espacial na ausência de mapeamento e/ou codificação de símbolo na transmissão foi proposto em (JEGANATHAN et al., 2009), denominado modulação por chaveamento espacial (SSK - space shift keying). Neste sistema mais simples que o SM clássico, a informação a ser transmitida é mapeada simplesmente através das antenas transmissoras, ou seja, a forma de onda transmitida não carrega informação. Esta característica faz da detecção SSK menos complexa que a detecção SM, porém mantendo o mesmo ganho de multiplexação do SM mencionado em (MESLEH, 2008).

Ademais, quando a implantação de antenas for um limitante, um esquema variante do SSK pode ser usado: trata-se do esquema SSK generalizado (GSSK - generalized SSK) (JEGANATHAN; GHRAYEB; SZCZECINSKI, 2008a). O conceito GSSK está no uso da combinação dos índices das antenas de transmissão, contrastando com o uso de apenas um único índice utilizado no esquema SSK. Em(JEGANATHAN; GHRAYEB; SZCZECINSKI, 2008a) desenvolveu-se um critério de otimização para o projeto do diagrama da constelação espacial, isto é, a escolha do conjunto ótimo de antenas ativas e inativas, sob o ponto de vista da minimização da taxa de erro de bit. O ganho obtido com o SSK se mantém no GSSK, porém ao custo da manutenção de sincronismo entre as antenas transmissoras e também necessitar de múltiplas conexões de rádio frequência. De fato, observa-se que o esquema SSK é um caso particular do GSSK, quando somente uma antena é empregada no transmissor a cada período de símbolo.

Este trabalho está dividido em seis partes, além desta seção introdutória. Na seção II descreve-se o modelo de sistema a ser utilizado neste trabalho, incluindo detalhamento do transmissor e receptor. Nas seções III e IV também são descritos os modelos de sistema para SSK e GSSK, respectivamente. A complexidade e os resultados de desempenho para cada esquema de modulação citados anteriormente são apresentados e analisados nas seções $\mathrm{V}$ e VI, respectivamente. Por fim, na seção VII são apresentadas a principais conclusões deste trabalho.

Notação empregada neste trabalho: símbolos minúsculos em negrito representam vetores e maiúsculos em negritos, matrizes. Símbolos itálicos denotam valores escalares. As notações $(\cdot)^{\mathrm{T}},(\cdot)^{\mathrm{H}}$, $\|\cdot\|$ e $\|\cdot\|_{F}$ representam transposta, Hermitiano, norma 
dois $^{3}$ e norma de Frobenius ${ }^{4}$ de uma matriz ou vetor, respectivamente. O operador $\mid \cdot$ denota valor absoluto de um escalar. $\mathrm{CN}\left(\mu, \sigma^{2}\right)$ representa uma distribuição Gaussiana complexa de uma variável aleatória com média $\mu$ e variância $\sigma^{2}$, sendo as partes real e imaginária caracterizadas por distribuições

Gaussianas independentes $\mathrm{N}\left(\mu, \frac{1}{2} \sigma^{2}\right) \cdot P(\cdot)$ é a probabilidade de ocorrência de um evento; $\mathrm{p}_{\mathrm{Y}}$ denota a função densidade probabilidade da variável aleatória $\mathbf{y}$ e $\mathrm{E}_{\mathrm{x}}[\cdot]$ denota esperança estatística com respeito à variável $\mathrm{x}$.

\section{Modulação Espacial}

Um esboço topológico para a modulação espacial no contexto de canal MIMO é indicado na Fig. 1 (MESLEH et al., 2006). Neste esquema, $h_{\mathrm{v} \tau}$ é o ganho de canal entre a antena de transmissão $\tau$ e a antena de recepção $v$. $N_{\mathrm{r}}$ é o número de antenas de recepção. Para modulação M-QAM, $\mathrm{m}=\log _{2}(M)$ é o número de bits/símbolo; b é um vetor de $\mathrm{n}$ bits a ser transmitido. $\mathrm{O}$ vetor binário é mapeado em outro vetor $\mathrm{x}=\left[\begin{array}{lll}0 & x_{1} \cdots & 0\end{array}\right]^{T}$ de tamanho $N^{t}$ onde somente um elemento é diferente de zero. O símbolo de número $l$ no vetor resultante $\mathbf{x}$ é $x_{1}$, onde $t$ é o número da antena de transmissão mapeada, $t \in\left[1: N_{t}\right]$.

Figura 1 - Modelo topológico para o sistema com modulação espacial.

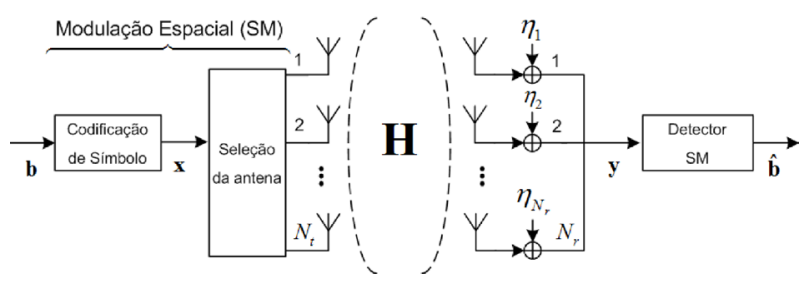

Fonte: MESLEH et al., 2006.
O símbolo $x_{1}$ é transmitido pela antena de número $l$ sobre o canal MIMO, denotado pela matrix $\mathbf{H}$, caracterizado por um canal Rayleigh plano $^{5}$ com amostras independentes e identicamente distribuídas (i.i.d.) de acordo com CN $(0,1)$. Observe que a matriz de canal $\mathbf{H}$ pode ser escrita como um conjunto de vetores, onde cada vetor corresponde ao ganho de caminho do canal entre a antena de transmissão $v$ e as $N_{r}$ antenas de recepção:

$$
\mathbf{H}=\left[\begin{array}{llllll}
\mathbf{h}_{1} & \mathbf{h}_{2} & \cdots & \mathbf{h}_{\nu} & \cdots & \mathbf{h}_{N_{t}}
\end{array}\right]
$$

sendo

$\mathbf{h}_{\nu}=\sqrt{\rho}\left[\begin{array}{llll}h_{1, \nu} & h_{2, \nu} & \cdots & h_{N_{r}, \nu}\end{array}\right]^{T}$

em que $p$ é a relação sinal ruído (SNR - Signal to Noise Ratio) média em cada antena receptora.

$\mathrm{O}$ vetor recebido é dado por:

$$
\mathbf{y}=\mathbf{h}_{(\nu=\iota)} x_{\iota}+\boldsymbol{\eta}
$$

sendo $\boldsymbol{\eta}$ o vetor do ruído aditivo Gaussiano branco (AWGN - Additive White Gaussian Noise)

$$
\boldsymbol{\eta}=\left[\begin{array}{llll}
\eta_{1} & \eta_{2} & \cdots & \eta_{N_{r}}
\end{array}\right]^{T} \sim \mathrm{CN}(0,1)
$$

O número de bits de informações transmitidos, $n$, pode ser ajustado em dois diferentes e independentes modos: a) ajustando-se a ordem de modulação do sinal; b) número de símbolos associado a cada antena na etapa da modulação espacial. Por exemplo, três bits de informação mapeiam um símbolo entre $2^{3}=8$ possíveis símbolos, sendo estes símbolos igualmente divididos entre quatro antenas de transmissão, porém empregando-se modulação BPSK, como mostrado na Fig. 2.a. Alternativamente, empregando-se duas antenas de transmissão ao invés de quatro, três bits podem ser

${ }^{3}$ A norma 2 ou norma Euclidiana de um vetor é definida como $\|\mathbf{x}\|_{2}=\left(\sum_{i=1}^{n} x_{i}^{2}\right)^{\frac{1}{2}}$, sendo $x_{i}$ o i-ésimo elemento do vetor $\mathbf{x}$.
${ }^{4}$ A norma de Frobenius de uma matriz é definida como $\|\mathbf{A}\|_{F}=\left(\sum_{i=1}^{m} \sum_{j=1}^{n} a_{i j}^{2}\right)^{\frac{1}{2}}$, sendo $\mathrm{a}_{\mathrm{ij}}$ o elemento da i-ésima linha e j-ésima
coluna da matriz A.

5 Não seletivo em freqüência. 
enviados se a técnica de modulação for trocada para a modulação 4QAM (ou QPSK) como mostrado na Fig. 2.b. Similarmente, para transmitir quatro bits, podem ser combinados a modulação BPSK e oito antenas ou modulação 4QAM e quatro antenas de transmissão, ou ainda modulação 8QAM combinada a duas antenas. Note-se então que a mesma taxa de dados pode ser alcançada com as três configurações. Em geral, o número de bits que pode ser transmitido usando modulação espacial é dado por:

$$
n=\log _{2}\left(N_{t}\right)+m=\log _{2}\left(M N_{t}\right)
$$

\section{Estimativa do Símbolo Transmitido}

Na modulação espacial, a informação binária é mapeada combinando-se a designação de símbolo (modulação digital M-ária) e do índice da antena de transmissão. Observe que, no receptor, a estimação correta do índice da antena de transmissão é decisiva na obtenção de um desempenho adequado em termos de taxa de erro de bit. Existem duas formas de se estimar o índice da antena e o símbolo transmitido: a sub-ótima (MESLEH et al., 2006) e a ótima, que emprega a técnica de máxima verossimilhança (ML - Maximum Likelihood) (JEGANATHAN; GHRAYEB; SZCZECINSKI, 2008b).

Figura 2 - Modulação Espacial: a) 3 bits BPSK com 4 antenas; b) 3 bits 4QAM com 2 antenas.

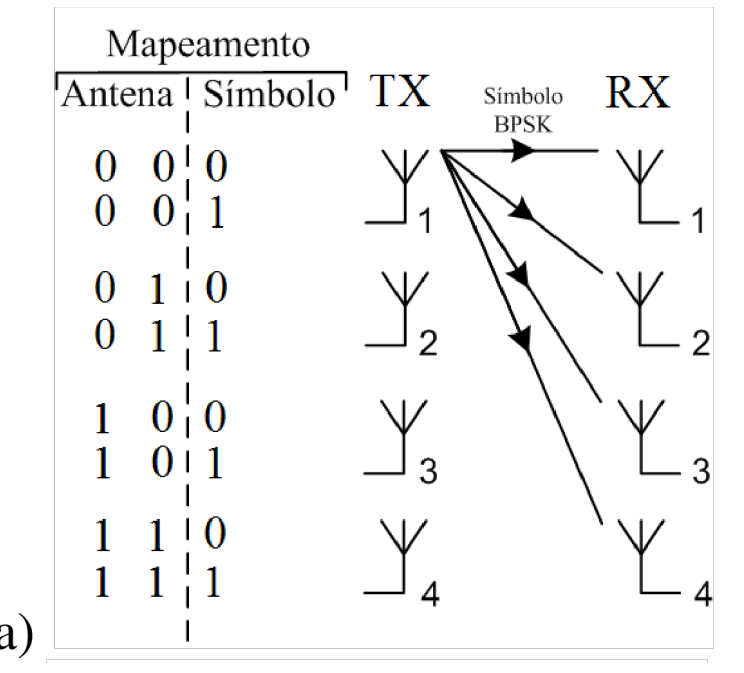

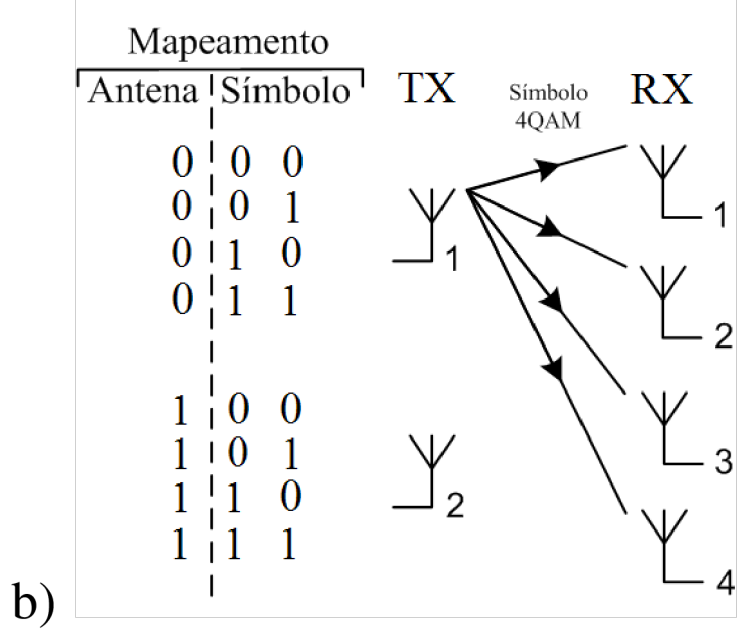

Fonte: Mesleh et al. (2006).

\section{Detecção Sub-Ótima}

$\mathrm{O}$ vetor recebido $\mathbf{y}$ é iterativamente multiplicado pelos respectivos ganhos de percurso do canal, admitido conhecidos na recepção, tendo em vista estimar tanto o símbolo transmitido como o índice da antena de transmissão da seguinte forma (MESLEH et al., 2006):

$$
\begin{aligned}
& z_{j}=\frac{\mathbf{h}_{j}^{H} \mathbf{y}}{\left\|\mathbf{h}_{j}\right\|_{F}^{2}}, \quad \text { para } j=1: N_{t} \\
& \mathbf{z}=\left[\begin{array}{llll}
z_{1} & z_{2} & \cdots & z_{N_{t}}
\end{array}\right]^{T}
\end{aligned}
$$

$\tilde{\iota}=\arg \max _{j}|\mathbf{z}|$

$\tilde{x}_{\iota}=Q\left(\mathbf{z}_{(j=\tilde{\iota})}\right)$

em que $\tilde{\iota}$ é o índice estimado da antena, $\tilde{x}_{\iota}$ é o símbolo estimado e $Q($ ) é a função de quantização (slicing) relativa a constelação utilizada.

Note-se que para a detecção dos símbolos no receptor em (MESLEH et al., 2006) faz-se necessário o uso de algum tipo de normalização no canal antes da aplicação de (7)-(8). Uma maneira de assegurar a detecção correta do índice da antena de transmissão consiste em normalizar 
os coeficientes de canal antes da transmissão, i.e., fazendo-se $\left\|\mathbf{h}_{j}\right\|_{F}^{2}=c$ para todos os $j$, onde $c$ é uma constante (JEGANATHAN; GHRAYEB; SZCZECINSKI, 2008b). Esta condição pode ser vista substituindo-se (3) (na ausência de ruído) em (5), obtendo $z_{k}=\frac{\mathbf{h}_{k}^{H} \mathbf{h}_{t} x_{i}}{\left\|\mathbf{h}_{k}\right\|_{F}^{2}}$. Para se detectar corretamente o índice da antena transmissora, ou seja, $k=\imath$, é necessário que $\frac{\mathbf{h}_{k}^{H} \mathbf{h}_{\imath}}{\left\|\mathbf{h}_{k}\right\|_{F}^{2}}<1$. Utilizando

a desigualdade de Cauchy do lado esquerdo desta equação, obtém-se:

$$
\begin{array}{r}
\left\|\mathbf{h}_{k}^{H}\right\|_{F}\left\|\mathbf{h}_{\iota}\right\|_{F} \leq\left\|\mathbf{h}_{k}\right\|_{F}^{2} \\
\left\|\mathbf{h}_{\iota}\right\|_{F} \leq\left\|\mathbf{h}_{k}\right\|_{F}
\end{array}
$$

pois $\left\|\mathbf{h}_{k}^{H}\right\|_{F}=\left\|\mathbf{h}_{k}\right\|_{F}$.

Este resultado é uma condição necessária para que o índice da antena transmissora seja estimado corretamente na ausência de ruído. Esta condição faz-se necessária para o correto funcionamento do detector baseado na métrica MRC (maximum ratio combining), pois para evitar detecção errônea, cada antena transmissora/receptora deve ter um canal com mesmo peso para comparação, ou seja, devem estar normalizados por um fator comum.

Assumindo estimativa correta de $\tilde{\iota} \mathrm{e} \tilde{x}_{\iota}$, o receptor poderá então decodificar direta e corretamente os bits de informação originalmente transmitidos. A estimativa do índice da antena de transmissão é baseada na correlação cruzada entre os diferentes canais de percurso. Portanto, da mesma forma que na técnica de multiplexação espacial, o desempenho do algoritmo de deteç̧ão/decodificação SM depende da correlação do canal, ou seja, se os coeficientes instantâneos de canal, $\mathbf{h}_{\mathrm{t}}$ e $\mathbf{h}_{\mathrm{k}}$, nas $N_{\mathrm{r}}$ antenas de recepção oriundos das antenas de transmissão com índices $l, k \in\left[1: N_{t}\right]$ resultarem muito semelhantes entre si, então a desigualdade em (9) nem sempre será válida, impactando negativamente no desempenho SER/BER do sistema SM. Por sua vez, a correlação dos coeficientes de canal no esquema SM depende tão somente das características do canal e não do espaçamento entre as antenas de transmissão já que somente uma antena transmite de cada vez, principalmente se o período de ativação das antenas for superior ao tempo de coerência do canal sem fio.

\section{Detecção Ótima}

Já que a entrada do canal é assumida ser igualmente equiprovável, o detector ótimo (JEGANATHAN; GHRAYEB; SZCZECINSKI, 2008b) pode ser baseado no princípio da máxima verossimilhança conjunta (jointly ML), ou seja, em termos de otimização, encontrar os índices j e q tal que:

$$
\begin{aligned}
{\left[\tilde{\iota}_{M L}, \tilde{x}_{\iota M L}\right] } & =\arg \max _{j, q} p_{\mathbf{Y}}\left(\mathbf{y} \mid \mathbf{x}_{j q}, \mathbf{H}\right) \\
& =\arg \min _{j, q}\left\|\mathbf{y}-\mathbf{g}_{j q}\right\|^{2}
\end{aligned}
$$

sendo: $\mathbf{g}_{j q}=\mathbf{h}_{j} x_{q}$, com $1<j<N_{t}, 1<q<M$, e $p_{\mathbf{Y}}\left(\mathbf{y} \mid \mathbf{x}_{j q}, \mathbf{H}\right)=\pi^{-N_{r}} \exp \left(-\left\|\mathbf{y}-\mathbf{H} \mathbf{x}_{j q}\right\|_{F}^{2}\right)$ é a função

densidade de probabilidade (PDF) de $\mathbf{y}$, condicionada a $\quad \mathbf{x}_{\mathrm{jk}} \quad$ e $\quad \mathbf{H} \quad$ (JEGANATHAN; GHRAYEB; SZCZECINSKI, 2008b).

Da definição de norma Euclidiana (LAUB, 2005), tem-se:

$$
\begin{aligned}
\left\|\mathbf{y}-\mathbf{g}_{j q}\right\|^{2} & =\left(\mathbf{y}-\mathbf{g}_{j q}\right)^{H}\left(\mathbf{y}-\mathbf{g}_{j q}\right) \\
& =\left(\mathbf{y}^{H}-\mathbf{g}_{j q}^{H}\right)\left(\mathbf{y}-\mathbf{g}_{j q}\right) \\
& =\mathbf{y}^{H} \mathbf{y}-\mathbf{y}^{H} \mathbf{g}_{j q}-\mathbf{g}_{j q}^{H} \mathbf{y}+\mathbf{g}_{j q}^{H} \mathbf{g}_{j q}
\end{aligned}
$$

Note-se que o termo $\mathbf{y}^{H} \mathbf{y}$ é comum a todas as métricas de decisão, podendo desta forma ser desconsiderado no cômputo de(10). Adicionalmente, dado que o terceiro termo é igual ao conjugado do segundo termo, ou seja, $\mathbf{y}^{H} \mathbf{g}_{j q}=\overline{\mathbf{g}_{j q}^{H} \mathbf{y}}$ (LAUB, 2005) e somente o coeficiente real da soma destes termos é usado na métrica de decisão, obtém-se a simplificação:

$$
\begin{aligned}
\left\|\mathbf{y}-\mathbf{g}_{j q}\right\|^{2} & =-2 \operatorname{Re}\left\{\mathbf{y}^{H} \mathbf{g}_{j q}\right\}+\mathbf{g}_{j q}^{H} \mathbf{g}_{j q} \\
& =\left\|\mathbf{g}_{j q}\right\|^{2}-2 \operatorname{Re}\left\{\mathbf{y}^{H} \mathbf{g}_{j q}\right\}
\end{aligned}
$$


sendo $\left\|\mathbf{g}_{j q}\right\|^{2}=\mathbf{g}_{j q}^{H} \mathbf{g}_{j q}$. Portanto, a detecção ótima para o esquema de transmissão SM pode ser obtida de forma mais compacta como:

$$
\left[\tilde{\iota}_{M L}, \tilde{x}_{\iota M L}\right]=\arg \min _{j, q}\left(\left\|\mathbf{g}_{j q}\right\|^{2}-2 \operatorname{Re}\left\{\mathbf{y}^{H} \mathbf{g}_{j q}\right\}\right)
$$

Com isso, pode-se verificar que a detecção ótima requer uma detecção conjunta do índice da antena e do símbolo. Adicionalmente, para o detector SM ótimo, a condição de normalização de canal antes da transmissão, descrita na seção II-A1, não se faz necessária.

\section{Modulação por Chaveamento Espacial (SSK)}

Modulação por chaveamento espacial é um esquema de modulação de baixa complexidade baseado nos conceitos de modulação espacial. Nesta técnica, a diversidade produzida por múltiplos canais desvanecidos e independentes é utilizada para obter melhor desempenho que técnicas de modulação por amplitude e fase convencionais (APM - amplitude) phase modulation). O esquema de modulação SSK utiliza o índice da antena ativa durante a transmissão na codificação da informação, ao invés do símbolo transmitido em si. Esta ausência de informações nos símbolos simplifica o projeto tanto do transmissor como do receptor, uma vez que os blocos iniciais de modulação necessários à transmissão e detecção APM convencional, como por exemplo os blocos necessários à detecção coerente, são eliminados. Desempenhos próximos aos obtidos com a SM convencional podem ser obtidos com a modulação SSK, porém com a vantagem da redução na complexidade de detecção (JEGANATHAN et al., 2009).

\section{Descrição do Esquema SSK}

Na Fig. 3 é ilustrado o modelo geral de um sistema MIMO com $N_{r}$ antenas receptoras e $N_{t}$ antenas transmissoras. Uma sequência aleatória de bits $\mathbf{b}=\left[\begin{array}{llll}b_{1} & b_{2} & \cdots & b_{k}\end{array}\right]$ é mapeada a cada grupo de $m=\log _{2}\left(N_{t}\right)$ em outro vetor $\mathbf{x}=\left[\begin{array}{llll}x_{1} & x_{2} & \cdots & x_{N_{t}}\end{array}\right]^{T}$.
Este sinal é então transmitido sobre o canal MIMO $\mathbf{H}$ definido em (1), caracterizado por um canal Rayleigh não seletivo em frequência e sofre o efeito do ruído AWGN $\boldsymbol{\eta}=\left[\begin{array}{llll}\eta_{1} & \eta_{2} & \cdots & \eta_{N_{r}}\end{array}\right]^{T}$. O sinal recebido é então dado por:

$$
\mathbf{y}=\mathbf{H x}+\eta
$$

sendo que $\mathbf{H}$ e $\boldsymbol{\eta}$ constituídos por amostras i.i.d. de acordo com $\mathrm{CN}(0,1)$.

No receptor, o detector SSK estima o índice da antena usada durante a transmissão e decodifica os bits de informação originalmente transmitidos, gerando o vetor de bits estimados $\hat{\mathbf{b}}$.

Figura 3 - Modelo topológico para sistemas MIMO com antenas transmissoras e antenas receptoras.

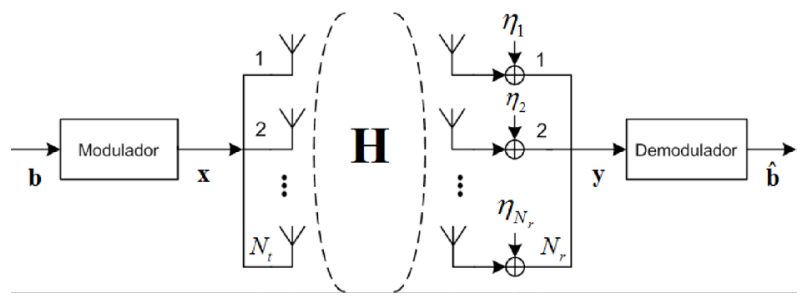

Fonte: Do Autor

\section{Transmissão e Detecção}

A modulação SSK consiste de grupos de $m$ bits que são mapeados em um símbolo, que então é transmitido energizando-se a j-ésima antena de transmissão. O símbolo $x_{j}$ é admitido sendo $x_{j}=1$ para todo $j$, ou seja, não contém informação. Porém, a posição deste símbolo dentro do vetor $\mathbf{x}$ contém a informação. De forma análoga à modulação SM, o vetor $\mathbf{x}$ indica a antena ativa durante a transmissão enquanto todas as outras permanecem desativadas e apresenta o seguinte formato:

$$
\mathbf{x}_{j} \triangleq\left[\begin{array}{lllllll}
0 & 0 & \cdots & 1 & 0 & \cdots & 0
\end{array}\right]^{T}
$$

sendo que o elemento $1 \in \mathbf{x}_{j}$ ocupa a $j$-ésima posição. Com isso, o sinal recebido quando a $j$-ésima antena é ativada será dado por:

$$
\mathbf{y}=\mathbf{h}_{j}+\boldsymbol{\eta}
$$


sendo $\mathbf{h}_{j}$ a j-ésima coluna de $\mathbf{H}$.

Uma vez que a entrada do canal é assumida igualmente equiprovável, o detector ótimo resultante (JEGANATHAN et al., 2009) para o esquema SSK, similarmente ao detector ótimo SM, será obtido a partir do princípio da verossimilhança, sendo dado por:

$$
\begin{aligned}
\widehat{j} & =\arg \max _{j} p_{\mathbf{Y}}\left(\mathbf{y} \mid \mathbf{x}_{j}, \mathbf{H}\right)=\arg \min _{j}\left\|\mathbf{y}-\mathbf{h}_{j}\right\|^{2} \\
& =\arg \max _{j} \operatorname{Re}\left\{\left(\mathbf{y}-\frac{\mathbf{h}_{j}}{2}\right)^{H} \mathbf{h}_{j}\right\}
\end{aligned}
$$

sendo $\hat{\jmath}$ o índice da antena estimado, $1<j<N_{t}$, que $\operatorname{maximiza}(17)$ e $p_{\mathbf{Y}}=\left(\mathbf{y} \mid \mathbf{x}_{j}, \mathbf{H}\right)=\pi^{-N_{r}} \exp \left(-\left\|\mathbf{y}-\mathbf{H} \mathbf{x}_{j}\right\|_{F}^{2}\right)$ é a PDF condicional de (JEGANATHAN et al., 2009).

\section{Modulação por Chaveamento Espacial Generalizado (GSSK)}

A modulação por chaveamento espacial generalizado aproveita o princípio da independência dos sinais através dos canais gerados entre cada antena transmissora e a(s) antena(s) receptora(s), tendo em vista melhorar o desempenho e a confiabilidade de recepção dos sinais em sistemas de comunicação sem fio. O GSSK explora o domínio espacial para modular a informação; no entanto, diferentemente do que ocorre no esquema SM convencional, no esquema GSSK somente os índices das antenas transmissoras contém informação.

\section{Descrição do Esquema GSSK}

A Fig. 3 ilustra o esquema geral MIMO GSSK, sendo composto por $N_{t}$ e $N_{r}$ antenas transmissoras e receptoras, respectivamente. Grupos de $m$ bits de uma sequência aleatória de informação binária independente $\mathbf{b}=\left[\begin{array}{llll}b_{1} & b_{2} & \cdots & b_{k}\end{array}\right]$ são mapeados em um vetor $\mathbf{x}=\left[\begin{array}{llll}\mathrm{x}_{1} & \mathrm{x}_{2} & \cdots & \mathrm{x}_{\mathrm{N}}\end{array}\right]^{T}$ que é constituído por pontos da constelação GSSK. Neste esquema, somente $n_{\mathrm{t}}$ antenas são ativadas durante a transmissão, o que implica que somente $n_{\mathrm{t}}$ elementos de $\mathbf{x}$ serão diferentes de zero. Este sinal é então transmitido sobre o canal MIMO, caracterizado pela matriz de canal $\mathbf{H}$ definida na equação (1), admitido não seletivo em frequência, com distribuição estatística de Rayleigh para as amplitudes e amostras i.i.d, de acordo com . O sinal recebido ainda está sujeito ao efeito aditivo do ruído AWGN, caracterizado pelo vetor $\boldsymbol{\eta}=\left[\begin{array}{llll}\eta_{1} & \eta_{2} & \cdots & \eta_{N_{r}}\end{array}\right]^{T}$, resultando em:

$$
\mathbf{y}=\mathbf{H x}+\boldsymbol{\eta}
$$

sendo $\boldsymbol{\eta}$ constituída por amostras i.i.d. de acordo com $\mathrm{CN}(0,1)$.

No receptor, o demodulador GSSK estima os índices das antenas usadas na transmissão e então decodifica o símbolo no vetor estimado de informação $\hat{\mathbf{b}}$.

\section{Transmissão GSSK}

O ponto fundamental do esquema GSSK está no fato de que a informação transmitida está contida apenas nos índices das antenas de transmissão. Um sistema GSSK usando $n_{\mathrm{t}}$ antenas ativas na transmissão de um total de antenas no transmissor, é possível formar uma constelação com pontos. Dentre este total de pontos, será escolhida uma combinação de pontos em potência de dois. Por exemplo, se $n_{t}=2$ e $N_{t}=7$, obtém-se um total de $\mathrm{M}^{\prime}=21$ combinações. Com isso, a constelação a ser utilizada será obtida a partir de $M=2^{\left\lfloor\log _{2} M^{\prime}\right\rfloor}$, resultando, neste exemplo, em $M=16$ pontos.

Observa-se que o conjunto de combinações de antenas $X$ pode ser escolhido aleatoriamente, dentre as possíveis combinações das $N_{t}$ antenas transmissoras. No entanto, como será visto na seção IV-B, é possível obter uma seleção ótima de antenas no sentido de minimizar a taxa de erro da informação detectada. 
Após o conjunto $X$ ser escolhido, grupos de $m=\log _{2} M$ bits são mapeados em um vetor $\mathbf{x}_{\mathbf{j}}$, em que $\mathbf{j} \in X$ representa o vetor de índices das antenas para um dado padrão de $m$. $\mathrm{O}$ vetor $\mathbf{x}_{\mathbf{j}}$ especifica as antenas ativas e inativas e tem a seguinte forma:

$$
\mathbf{x}_{\mathbf{j}}=\left[\begin{array}{lllllll}
1 & 0 & \cdots & 0 & 1 & \cdots & 1
\end{array}\right]^{T}
$$

sendo que $\mathbf{x}_{\mathbf{j}}$ possui $n_{t}$ elementos diferentes de zero. Com isto, a forma de onda no receptor é dada por:

$$
\mathbf{y}=\mathbf{h}_{\mathbf{j}, \text { eff }}+\boldsymbol{\eta}
$$

sendo $\mathbf{h}_{\mathbf{j}, \text { fff }}=\mathbf{h}_{\mathbf{j}(1)}+\mathbf{h}_{\mathbf{j}(2)}+\cdots+\mathbf{h}_{\mathbf{j}\left(n_{t}\right)}$ com

indicando $\mathbf{j}(\cdot) \in\left\{1,2, \cdots, N_{t}\right\}$ o índice da coluna da matriz de canal H. Como há mais de uma antena ativa por transmissão, cada antena receptora receberá formas de ondas oriundas destas antenas ativas. Para representar este efeito, $\mathbf{h}_{\text {jeff }}$ é obtida como a soma das $n_{t}$ colunas distintas da matriz $\mathbf{H}$, ou seja, os caminhos percorridos pelos sinais transmitidos no canal MIMO.

\section{Detecção GSSK}

A função principal do detector é estimar os índices das antenas utilizadas na transmissão dos dados. Uma vez que as entradas do canal são assumidas equiprováveis, o detector ótimo resultante (JEGANATHAN; GHRAYEB; SZCZECINSKI, 2008a), similarmente ao detector ótimo SM, é obtido a partir do princípio de verossimilhança:

$$
\begin{aligned}
\widehat{\mathbf{k}} & =\arg \max _{\mathbf{j}} p_{\mathbf{Y}}\left(\mathbf{y} \mid \mathbf{x}_{\mathbf{j}}, \mathbf{H}\right)=\arg \min _{\mathbf{j}}\left\|\mathbf{y}-\mathbf{h}_{\mathbf{j}, \text { eff }}\right\|^{2} \\
& =\arg \max _{\mathbf{j}} \operatorname{Re}\left\{\left(\mathbf{y}-\frac{\mathbf{h}_{\mathbf{j}, \text { eff }}}{2}\right)^{H} \mathbf{h}_{\mathbf{j}, \text { eff }}\right\}
\end{aligned}
$$

em que representa o vetor dos índices estimados para as antenas que maximizam (21) e é a PDF condicional de (JEGANATHAN; GHRAYEB; SZCZECINSKI, 2008a), dada por:

$$
p_{\mathbf{Y}}\left(\mathbf{y} \mid \mathbf{x}_{\mathbf{j}}, \mathbf{H}\right)=\frac{1}{\pi^{N_{r}}} \exp \left(-\left\|\mathbf{y}-\mathbf{H x}_{\mathbf{j}}\right\|_{F}^{2}\right)
$$

A métrica de decisão do esquema GSSK baseiase em um problema de maximização sobre todas as $M$ colunas efetivas da matriz de canal $\mathbf{H}$. Portanto, a detecção GSSK depende somente das características do canal.

\section{Constelação Ótima}

A escolha da constelação ótima $(X)$ para o esquema GSSK é feita em termos da minimização da taxa de erro de bit. Em (JEGANATHAN; GHRAYEB; SZCZECINSKI, 2008a) foi mostrado que a seleção ótima de antenas apresenta uma grande complexidade, pois para cada $N_{t}$ escolhido terão $N_{t}-1$ possíveis valores para $n_{t}$. Também foi demonstrado (JEGANATHAN; GHRAYEB; SZCZECINSKI, 2008a) que o problema de designação do conjunto ótimo de antenas pode ser interpretado como uma escolha de combinações de antenas que são diferentes uma das outras o máximo possível. Para simplificar o problema de otimização relativo ao conjunto de antenas, neste trabalho assumiu-se que os seguintes parâmetros de projeto GSSK sejam conhecidos a priori: $N_{t}, n_{t}$, bem como $\mathrm{o}$ número de bits transmitidos, $\mathrm{m}$. Com isso, o problema de otimização simplifica-se:

$$
\hat{\chi}=\arg \max _{\chi} \sum_{\mathbf{i}} \sum_{\mathbf{j}} d(\mathbf{i}, \mathbf{j})
$$

sendo $\hat{\chi}$ a constelação ótima, $d(\mathbf{i}, \mathbf{j})$ o número de colunas distintas na matriz de canal $\mathbf{H}$ resultante entre $\mathbf{h}_{\mathbf{i} \text {,eff }}$ e $\mathbf{h}_{\mathbf{j} \text {,eff }}$ da constelação $\chi$. Portanto, dado um valor para $n_{t}$ e $N_{t}$, deve-se escolher o conjunto de antenas (constelação) completo tal que $d(\mathbf{i}, \mathbf{j})$ seja maximizado. Este problema de maximização pode ser interpretado como sendo o conjunto de pontos (sendo que cada ponto indica as antenas ativas naquele instante) que se diferem um do outro o máximo possível. Por exemplo, para uma taxa de 3 bits/s com $N_{t}=7$ e $n_{t}=2$ e por meio de simulação computacional da eq. (23), obtém-se o conjunto ótimo apresentado na Tabela $1 . \mathbf{h}_{\mathbf{j}, \text { eff }}$ é composto por 
combinações do vetor $\mathbf{J} \epsilon \hat{\chi}$, o qual contém o vetor de índices das antenas ativas para cada padrão dos dados de entrada, b . Com isso, por meio de análise dos vetores $\mathbf{j}$ e i é possível obter $d(\mathbf{i}, \mathbf{j})$ na eq. (23). Comparando o ponto $(1,2) \in \mathbf{j}$ com $(1,3) \in \mathbf{i}$ obtémse $d(\mathbf{i}, \mathbf{j})=2$, pois o número de colunas distintas da matriz de canal $\mathbf{H}$ resultante entre $\mathbf{h}_{\mathbf{j} \text {,eff }}$ e $\mathbf{h}_{\mathbf{i}, \text { eff }}$ será igual a dois. Da mesma forma, para $(1,2) \in \mathbf{j}$ com $(3,4) € \mathbf{i}$ obtém-se $d(\mathbf{i}, \mathbf{j})=4$.

Tabela 1 - Exemplo de constelação otimizada para GSSK.

\begin{tabular}{|c|c|c|}
\hline $\mathbf{b}=\left[\mathrm{b}_{1}, \mathrm{~b}_{2}, \mathrm{~b}_{3}\right]$ & $\mathbf{j}$ & $\mathbf{x j}=\left[\begin{array}{llll}x_{1} \ldots x_{4} & \ldots & x_{7}\end{array}\right]^{T}$ \\
\hline$\left[\begin{array}{lll}0 & 0 & 0\end{array}\right]$ & $(1,2)$ & {$\left[\begin{array}{lllllll}1 & 1 & 0 & 0 & 0 & 0 & 0\end{array}\right]^{T}$} \\
\hline$\left[\begin{array}{lll}0 & 0 & 1\end{array}\right]$ & $(1,3)$ & {$\left[\begin{array}{lllllll}1 & 0 & 1 & 0 & 0 & 0 & 0\end{array}\right]^{T}$} \\
\hline$\left[\begin{array}{llll}0 & 1 & 0\end{array}\right]$ & $(2,3)$ & {$\left[\begin{array}{lllllll}0 & 1 & 1 & 0 & 0 & 0 & 0\end{array}\right]^{T}$} \\
\hline$\left[\begin{array}{llll}0 & 1 & 1\end{array}\right]$ & $(2,4)$ & {$\left[\begin{array}{lllllll}0 & 1 & 0 & 1 & 0 & 0 & 0\end{array}\right]^{T}$} \\
\hline$\left[\begin{array}{lll}1 & 0 & 0\end{array}\right]$ & $(3,4)$ & {$\left[\begin{array}{lllllll}0 & 0 & 1 & 1 & 0 & 0 & 0\end{array}\right]^{T}$} \\
\hline$\left[\begin{array}{lll}1 & 0 & 1\end{array}\right]$ & $(4,5)$ & {$\left[\begin{array}{lllllll}0 & 0 & 0 & 1 & 1 & 0 & 0\end{array}\right]^{T}$} \\
\hline$\left[\begin{array}{lll}1 & 1 & 0\end{array}\right]$ & $(5,6)$ & {$\left[\begin{array}{lllllll}0 & 0 & 0 & 0 & 1 & 1 & 0\end{array}\right]^{T}$} \\
\hline$\left[\begin{array}{lll}1 & 1 & 1\end{array}\right]$ & $(6,7)$ & {$\left[\begin{array}{lllllll}0 & 0 & 0 & 0 & 0 & 1 & 1\end{array}\right]^{T}$} \\
\hline
\end{tabular}

Fonte: Do Autor

Nota-se pelo critério descrito em eq. (23) que pode haver mais de um conjunto que maximize o desempenho do esquema GSSK.

\section{Análise de Complexidade}

Esta seção traz uma análise comparada de complexidade para os esquemas de modulação espacial recentemente propostos na literatura (SM e SSK) e o esquema V-BLAST. A complexidade computacional estabelecida aqui é de fundamental importância na determinação da viabilidade de implementação destes esquemas, bem como permite estabelecer um quadro mais justo entre os diferentes esquemas de modulação espacial, principalmente no que se refere ao compromisso complexidade $\mathrm{x}$ desempenho. $\mathrm{A}$ análise da complexidade computacional formulada neste trabalho é similar à análise realizada em (MESLEH et al., 2006) e (NAIDOO; XU; QUAZI, 2011), em que somente multiplicações e adições de números complexos são considerados como operações no processo de detecção.

\section{Complexidade Computacional: Esquema SM}

O esquema SM proposto por Mesleh (MESLEH et al., 2006) realiza a detecção da informação por meio da estimativa sequencial do índice da antena transmissora e do símbolo transmitido. A detecção do índice da antena de transmissão é dada pelas eq. (5) e (7). Em (MESLEH et al., 2006) foi mostrado que o numerador de (5) resulta em $N_{r}$ multiplicações complexas e $\left(N_{r}-1\right)$ adições complexas. O quadrado da norma de Frobenius no denominador de (5) é obtido pela multiplicação do vetor $\mathbf{h}_{j}$ de tamanho $N_{r}$ pelo seu equivalente complexo conjugado. Esta operação requer $N_{r}$ multiplicações complexas e nenhuma adição complexa. Como a eq. (5) é calculada para todos os valores de $j \in\left[\right.$ 1: $\left.N_{t}\right], 3 N_{r} N_{t}-N_{t}$ operações são necessárias. $\mathrm{O}$ valor absoluto em (7) é obtido multiplicando-se cada elemento $\mathrm{z}_{j}$ com o seu respectivo complexo conjugado efetuando então a raiz quadrada desta multiplicação (MESLEH, 2007). Com isso, obtémse um total de $N_{t}$ multiplicações complexas e zero adição complexa. Portanto, a estimativa do índice da antena de transmissão requer $\delta_{\mathrm{ANT}}=3 N_{r} N_{t}$ operações complexas.

A complexidade da detecção do símbolo é obtida por meio de análise de operações complexas do slicer. Cada limiar de comparação do slicer é considerado como uma operação complexa. Dada a modulação M-QAM, em que $m=\log _{2}(M)$ é o número de bits/símbolo, a análise será dividida pela disposição da constelação no diagrama de pontos: quadrada e retangular. Basicamente, quando $m$ é um número par o diagrama formado por sua 
constelação apresenta forma quadrática, enquanto que para $m$ ímpar o formato é retangular. O slicer para $m$ par requer $2^{\left(\frac{2+m}{2}\right)}-2$ operações complexas. Para $m$ ímpar são necessárias $3.2^{\left(\frac{m-1}{2}\right)}-2$ operações complexas. Com isso, tem-se que a complexidade computacional total do detector SM sub-ótimo é dada por:

$$
\delta_{\mathrm{SM}-\mathrm{SUB}}=\left\{\begin{array}{l}
3 N_{r} N_{t}+2^{\left(\frac{2+m}{2}\right)}-2, \text { para } m \text { par } \\
3 N_{r} N_{t}+3.2^{\left(\frac{m-1}{2}\right)}-2, \text { para } m \text { ímpar }
\end{array}\right.
$$

Por sua vez, a complexidade do detector SM ótimo (SM-OD) será obtida pela análise da métrica de detecção ML dada pela eq. (13). O primeiro termo é simplificado como $\left\|\mathbf{h}_{j} x_{q}\right\|_{F}^{2}=\left\|\mathbf{h}_{j}\right\|_{F}^{2}\left|x_{q}\right|^{2}$, assim como em (JEGANATHAN; GHRAYEB; SZCZECINSKI, 2008b). O quadrado da norma de Frobenius $\left\|\mathbf{h}_{j} x_{q}\right\|_{F}^{2}$ requer $N_{r}$ multiplicações complexas $\mathrm{e}$ é computada para as $N_{t}$ antenas transmissoras, obtendo assim $N_{r} N_{t}$ operações complexas. De forma semelhante ao procedimento adotado para o detector sub-ótimo, o quadrado do módulo $\left|\mathrm{x}_{\mathrm{q}}\right|^{2}$ requer uma multiplicação complexa. Como esta operação é efetuada para q $\epsilon$ [1:M], obtém-se $M$ operações complexas. Nota-se que a complexidade do produto dos termos em não é considerada, pois envolve apenas valores reais e não contribui para a complexidade total. Deste modo, a complexidade obtida para o primeiro termo é dada por $N_{r} N_{t}+M$.

A complexidade do segundo termo em (13) é dependente do cômputo de $\mathbf{y}^{H} \mathbf{h}_{\mathrm{j} q}^{X}$ (NAIDOO; XU; QUAZI, 2011). O cálculo de $\mathbf{y}^{H} \mathbf{h}_{\mathrm{j}}$ requer $N_{r}$ multiplicações complexas e $N_{r}-1$ somas complexas. Efetuando esta operação para $j \in\left[1: N_{t}\right]$ obtém-se $N_{t}$ $\left(2 N_{r}-1\right)$ operações complexas. Como $\mathbf{y}^{H} \mathbf{h}_{\mathrm{j}}$ já foi calculado anteriormente, a sua multiplicação por $x_{q}$ requer uma multiplicação complexa. Esta operação é efetuada $M$ vezes para cada $j \in\left[1: N_{t}\right]$, totalizando assim $N_{t} M$ operações complexas. Com isso, o segundo termo apresenta $2 N_{r} N_{t}+N_{t} M-N_{t}$ operações complexas. Somando-se as complexidades dos dois termos, obtém-se a complexidade total para o detector ótimo:

$$
\delta_{\mathrm{SM}-\mathrm{OD}}=3 N_{r} N_{t}+N_{t} M-N_{t}+M
$$

\section{Complexidade para o Esquema SSK}

Similarmente à complexidade obtida para os detectores ótimo e sub-ótimo utilizados no esquema de transmissão SM clássico, a complexidade do detector para o esquema SSK será analisada em termos do número de multiplicações e adições complexas utilizadas no processo de detecção. A complexidade para o problema de detecção ótima SSK será feita pela análise do termo dominante $\left(\mathbf{y}-\frac{\mathbf{h}_{j}}{2}\right)^{H} \mathbf{h}_{j}$ da eq. (17). A soma de matrizes no termo $\left(\mathbf{y}-\frac{\mathbf{h}}{2}\right)^{H}$ realizado para as $N_{t}$ antenas transmissoras produz $N_{r} N_{t}$ operações complexas. A multiplicação no termo $\left(\mathbf{y}-\frac{\mathbf{h}_{j}}{2}\right)^{H} \mathbf{h}_{j} \mathrm{r}$ e q u e r $N_{r}$ multiplicações complexas e $\left(N_{r}-1\right)$ adições complexas. Efetuando esta operação para $j \in\left[1: N_{r}\right]$, obtém-se $N_{t}\left(2 N_{r}-1\right)$ operações complexas. Portanto, a complexidade para o detector ótimo SSK é dada por:

$$
\delta_{\mathrm{SSK}}=3 N_{r} N_{t}-N_{t}
$$

\section{Complexidade Computacional: V-BLAST}

A complexidade computacional do receptor V-BLAST de erro quadrático médio mínimo (MMSE - Minimum Mean Squared Error) foi obtido a partir de (MESLEH, 2007) para referência. O critério MMSE requer duas multiplicações de matrizes, uma inversão e uma adição (BOHNKE et al., 2003). A primeira multiplicação realizada requer $N_{t}^{2} N_{r}$ multiplicações complexas e $N_{t}^{2}\left(N_{r}-1\right)$ somas complexas. Por sua vez, a soma de matrizes requer $N_{t}^{2}$ adições complexas. A inversão de matriz será realizada utilizando o método de eliminação de Gauss. Em (GOLUB; LOAN, 1996) este 
método requer $2 n^{3} / 3$ flops $^{6}$ para matrizes contendo números reais. Como a análise de complexidade computacional neste trabalho considera apenas operações com números complexos, será considerado que uma multiplicação e uma adição complexa corresponde à seis e dois flops, respectivamente. Assim, para o pior caso, a inversão de matriz requer $4 N_{t}^{3}$ operações complexas. A segunda multiplicação de matrizes requer $3 N_{t}^{3}$ multiplicações complexas e $N_{t}^{2}\left(N_{t}-1\right)$ adições complexas. Com isso tem-se que são necessárias $\left(6 N_{t}^{3}+2 N_{r} N_{t}^{2}-N_{t}^{2}\right)$ operações complexas para este critério MMSE. Como V-BLAST executa estas operações para $j \in\left[1: N_{t}\right]$, o total de operações complexas no receptor é dado por:

$$
\delta_{\mathrm{V}-\mathrm{BLAST}}=\sum_{j=1}^{N_{t}}\left(6 j^{3}+2 N_{r} j^{2}-j^{2}\right)
$$

A Tabela 2 sintetiza as complexidades dos sistemas analisados.

Tabela 2 - Número de operações complexas para sistemas SM e V-BLAST

\begin{tabular}{ll}
\hline Sistema & \multicolumn{1}{c}{ Número de Operações } \\
\hline SM & $3 N_{r} N_{t}+2^{\left(\frac{2+m}{2}\right)}-2$, para $m$ ímpar \\
Sub-ótimo & $3 N_{r} N_{t}+3.2^{\left(\frac{m-1}{2}\right)}-2$, para $m$ ímpar \\
\hline SM Ótimo & $3 N_{r} N_{t}+N_{t} M-N_{t}+M$ \\
\hline SSK & $3 N_{r} N_{t}-N_{t}$ \\
\hline V-BLAST & $\sum_{j=1}^{N_{t}}\left(6 j^{3}+2 N_{r} j^{2}-j^{2}\right)$ \\
MMSE & $j_{j=1}$
\end{tabular}

Fonte: Do Autor
As complexidades computacionais para a modulação espacial com detecção ótima e subótima, modulação por chaveamento espacial e V-BLAST MMSE são apresentadas na Fig. 4. Nesta análise de complexidade, foi adotada modulação BPSK $(M=2)$ para um sistema com quatro antenas receptoras $(N r=4)$ e uma faixa de valores para antenas transmissoras no intervalo $N t \in$ [1:32]. Notase que a complexidade SSK é sempre menor que a complexidade apresentada por SM e SM-OD, enquanto que V-BLAST possui complexidade muito maior que os demais esquemas. Por exemplo, para $N t=8$ a complexidade V-BLAST é em torno de 100 vezes maior do que SM-OD. Observe-se também que as detecções sub-ótima e ótima para a modulação espacial possuem complexidades muito próximas para qualquer número de antenas transmissoras. Desta forma, a métrica desempenho complexidade será decidida pelo desempenho do sistema em termos de taxa de erro, a ser discutido na seção subsequente.

Por sua vez, a Fig. 5 mostra as complexidades SM, SM-OD, SSK e V-BLAST para $\mathrm{M}=2, N t=4$ e número de antenas receptoras no intervalo $N r \in$ [1: 16]. Notase que as complexidades dos esquemas SM e SMOD se equivalem para a faixa de valores de antenas transmissoras utilizada. Novamente, note-se que o sistema SSK é o que apresenta menor complexidade computacional.

Figura 4 - Complexidade em termos de operações complexas variando $N_{t}\left(\mathrm{M}=2\right.$ e $\left.N_{r}=4\right)$.

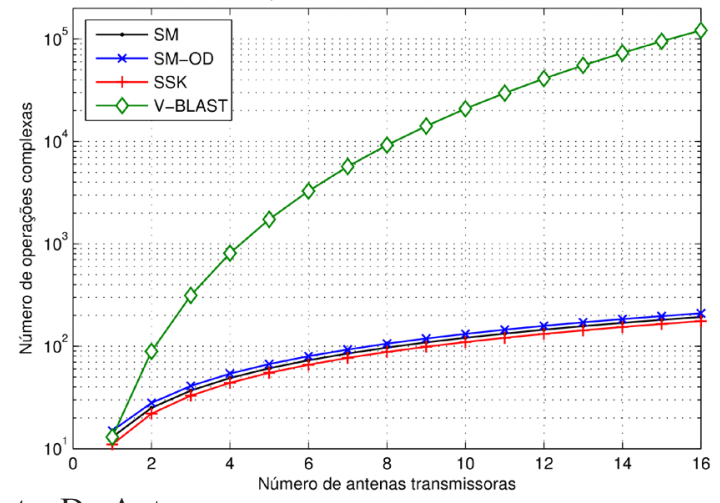

Fonte: Do Autor

\footnotetext{
${ }_{6}^{6}$ Operação de ponto flutuante (flop - float point operation) equivale a uma multiplicação ou uma adição de números reais.
} 
Figura 5 - Complexidade em termos de operações complexas variando $N_{r}\left(\mathrm{M}=2\right.$ e $\left.N_{r}=4\right)$.

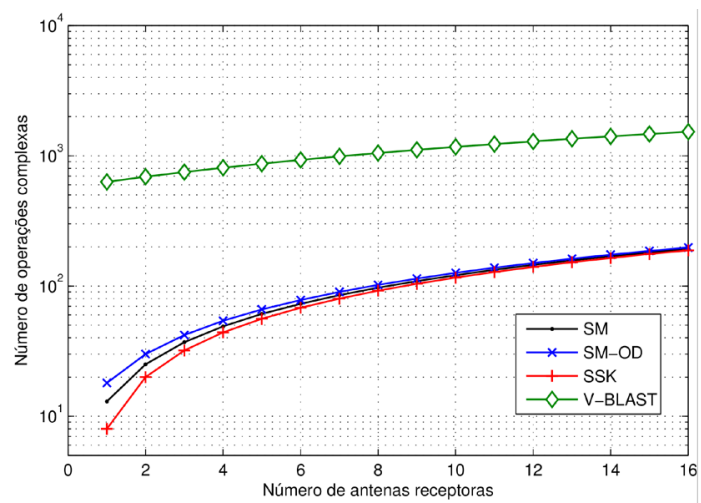

Fonte: Do Autor

Finalmente, a Fig. 6 coloca em perspectiva as complexidades dos esquemas SM, SM-OD, SSK e V-BLAST quando são incrementados o número de antenas transmissoras e receptoras. Neste gráfico, percebe-se que a ordem da complexidade V-BLAST é muito maior quando comparada com qualquer um dos esquemas de modulação espacial apresentados. Este comportamento é mais acentuado para a variação no número de antenas transmissoras, mostrando a sensibilidade do esquema V-BLAST com o número de antenas de transmissão. Evidencia-se também a proximidade existente entre a complexidade do detector ótimo e sub-ótimo para o esquema de modulação espacial (SM) e uma menor complexidade para o esquema SSK.

Figura 6 - Complexidade em termos de operações complexas variando $N_{t} \mathrm{e} N_{r}(\mathrm{M}=2)$.

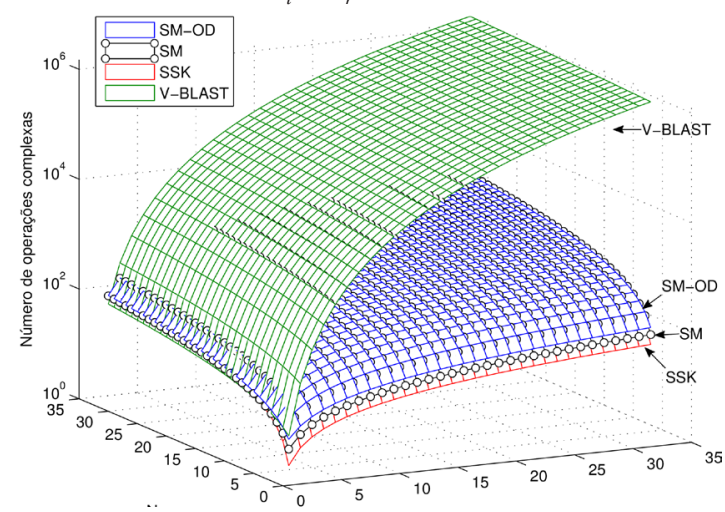

Fonte: Do Autor

\section{Resultados Numéricos}

Nesta seção são apresentados e comparados resultados de simulação para sistemas de modulação espacial e também V-BLAST. Os resultados numéricos para os sistemas em análise foram obtidos via simulação computacional Monte Carlo, em que a taxa de erro de bit é plotada como função da SNR média em cada antena receptora. Todas as configurações de sistema foram feitas de tal forma a resultar em um taxa de dados de 3bits/s.

\section{Desempenho para Esquema SM Convencional}

$\mathrm{Na}$ Fig. 7 são apresentados resultados de desempenho ilustrativos para SM com 3 bits de transmissão, quatro antenas transmissoras, quatro receptoras e constelação BPSK sob efeito do ruído AWGN. O canal adotado é Rayleigh plano. O desempenho para o sistema V-BLAST com taxa de dados de 3 bits/s com $N t=3$, modulação BPSK e receptor de erro quadrático médio mínimo (MMSE) com cancelamento de interferência sucessiva ordenada (OSIC - Ordered Successive Interference Cancellation) foi incluído para referência (JEGANATHAN; GHRAYEB; SZCZECINSKI, 2008b). A Tabela 3 sintetiza as principais características de canal e sistema topológico SM utilizados nesta seção.

Observa-se que o desempenho do detector SM convencional sub-ótimo é muito degradado, não sendo suficiente para atender a demanda da taxa de serviço atual. No outro extremo, o detector SM convencional ótimo apresenta um desempenho comparável a outras topologias já consolidadas na literatura, como por exemplo, V-BLAST (WOLNIANSKY et al., 1998). O ganho da modulação espacial com detecção ótima e canal convencional é de aproximadamente $1 \mathrm{~dB}$ sobre o esquema V-BLAST à taxa de erro de bit de $\mathrm{BER}=10^{-4}$. Adicionalmente, o desempenho do detector SM sub-ótimo é melhorado com a introdução da normalização do canal conforme 
descrito na subseção II-A1. Observa-se uma substancial melhoria em desempenho acima de $6 \mathrm{~dB}$ para o esquema SM com detecção sub-ótimo com canal normalizado. No entanto, a normalização do canal afeta negativamente o desempenho do detector ótimo. Neste caso, o desempenho do sistema é degradado em $\approx 5 \mathrm{~dB}$ nas regiões de médio e alto SNR.

Tabela 3 - Parâmetros de sistema e canal utilizados

\begin{tabular}{ll}
\hline Parâmetro & Valor adotado \\
\hline
\end{tabular}

\section{Canal}

Desvanecimento

Rayleigh Plano

Sistema SM

Taxa de Dados

3bits/s

Antenas Transmissoras

4

Antenas Receptoras

4

Modulação

BPSK

Relação Sinal-Ruído

$\mathrm{SNR}=[0: 18] \mathrm{dB}$

Fonte: Do Autor

Figura 7- Modulação Espacial: 3 bits/s com modulação BPSK e 4 antenas transmissoras. Canal normalizado (HN) e canal convencional (HC). Desempenho V-BLAST obtidos a partir de (JEGANATHAN; GHRAYEB; SZCZECINSKI, 2008b).

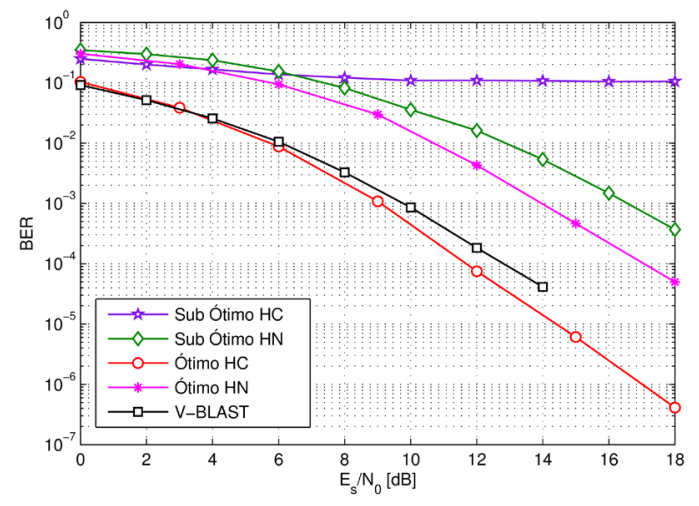

Fonte: Jeganathan; Ghrayeb; Szczecinski, (2008b).
Desta maneira, o detector ótimo com canal convencional, ou seja, canal sem normalização dos coeficientes antes da transmissão, torna-se a melhor escolha para o sistema SM. Além de resultar na menor taxa de erro de bit para uma mesma SNR quando comparado ao sub-ótimo, não requer normalização de canal para obter melhor desempenho. Para normalizar o canal antes da transmissão dos dados é necessário conhecimento prévio das condições do canal naquele instante, ou seja, um feedback do receptor. Esta condição impõe uma complexidade extra na implantação do sistema.

\section{Desempenho para o Esquema SSK}

$\mathrm{Na}$ Fig. 8 são apresentados resultados de desempenho para SSK e SM com 3 bits de transmissão sob efeito do ruído AWGN e canal Rayleigh plano. Utilizaram-se oito antenas transmissoras e quatro receptoras para o sistema SSK. Para se obter a mesma taxa de dados (3 bits/s), o sistema SM utilizado é composto por quatro antenas transmissoras e quatro receptoras e modulação BPSK. O desempenho do detector SM sub-ótimo foi obtido com as condições de canal descritas na seção II-A1, sendo que estas condições não foram aplicadas para os demais sistemas. Novamente, o desempenho do esquema V-BLAST com taxa de dados de 3 bits/s, $=3, N_{t}=3$ modulação BPSK e receptor MMSE-OSIC foi incluído para referência (JEGANATHAN; GHRAYEB; SZCZECINSKI, 2008b). A Tabela 4 sintetiza os parâmetros de sistema e canal utilizados na análise do esquema SSK. 
Tabela 4 - Parâmetros de sistema e canal empregados na análise SSK

\begin{tabular}{ll}
\hline Parâmetro & Valor adotado \\
\hline
\end{tabular}

Canal

Desvanecimento Rayleigh Plano

Sistema SSK

Taxa de Dados

$3 \mathrm{bits} / \mathrm{s}$

Antenas Transmissoras

8

Antenas Receptoras

4

Relação Sinal-Ruído

$\mathrm{SNR}=[0: 18] \mathrm{dB}$

Fonte: Do Autor

Figura 8: SSK, SM e V-BLAST: 3 bits/s. Canal com desvanecimento Rayleigh Plano.

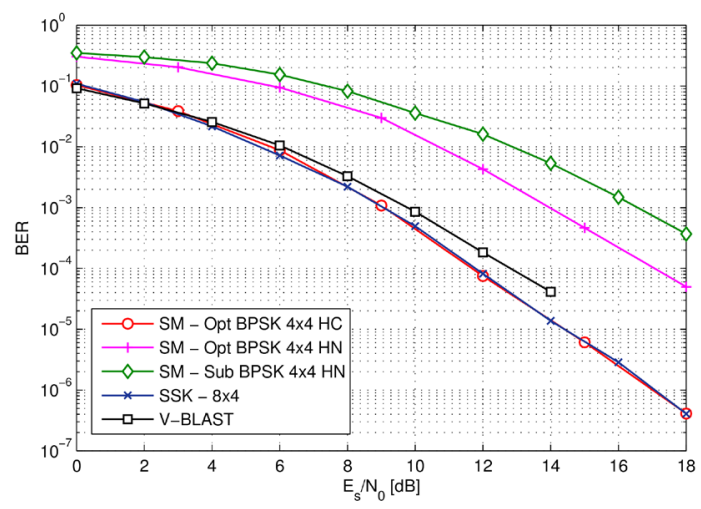

Fonte: Do Autor

Sob mesma taxa de dados, o desempenho SSK é praticamente idêntico ao obtido para detecção SM ótima, porém com menor complexidade. Esta baixa complexidade é atribuída ao fato dos símbolos na topologia SSK não carregarem informação, diferentemente do que é feito na modulação espacial e na modulação APM. Esta característica possibilita o uso de detectores não coerentes no receptor, porém é mais complexo fisicamente, pois utiliza maior número de antenas no transmissor (HAYKIN, 2001). Nota-se também o ganho de aproximadamente $1 \mathrm{~dB}$ sobre o esquema V-BLAST na taxa de erro de bit de $10^{-4}$. A ordem de diversidade deste sistema SSK é igual a quatro, obtida pela inclinação assintótica
$\left(S N R \rightarrow \infty\right.$ )(BIGLIERI et al., 2007) ou por $N_{r}$, uma vez que somente uma antena transmissora é ativada a cada instante.

Tanto para o esquema de transmissão SSK quanto para SM, o desempenho depende da estimativa correta do canal, pois a correta detecção é baseada na completa descorrelação entre os diversos canais criados entre as antenas transmissoras e receptoras.

\section{Desempenho para o Esquema GSSK}

$\mathrm{Na}$ Fig. 9 são apresentados resultados de desempenho para os esquema GSSK e SSK com 3 bits de transmissão sob efeito do ruído AWGN e canal Rayleigh plano. Utilizaram-se quatro antenas receptoras para o sistema GSSK enquanto que no transmissor foram utilizadas três diferentes configurações: $\left(N_{t}=5, n_{t}=2\right),\left(N_{t}=7, n_{t}=2\right)$ e $\left(N_{t}=8, n_{t}=1\right)$. O diagrama da constelação espacial utilizado nas simulações foi obtido a partir de simulação computacional da equação (23). O desempenho obtido para SSK foi obtido com a configuração $N_{t}=8$ e $N_{r}=4$. O desempenho para o esquema V-BLAST foi obtido $\operatorname{com} N_{t}=3$, modulação BPSK e receptor MMSE-OSIC (JEGANATHAN; GHRAYEB; SZCZECINSKI, 2008b). A Tabela 5 apresenta os principais parâmetros de canal e sistema utilizados nesta subseção.

Tabela 5 - Parâmetros de sistema e canal utilizados na análise GSSK

\begin{tabular}{ll}
\hline Parâmetro & Valor adotado \\
\hline & Canal
\end{tabular}

Desvanecimento

Rayleigh Plano

Sistema GSSK

Taxa de Dados

3bits/s

Antenas Transmissoras

$(8,1) ;(7,2) ;(5,2)$

Antenas Receptoras

4

Relação Sinal-Ruído

$\mathrm{SNR}=[0: 20] \mathrm{dB}$

Fonte: Do Autor 
O desempenho GSSK para $N_{t}=8$ e $n_{t}=1$ é idêntico ao obtido pelo sistema SSK. Como era esperado, percebe-se que SSK é um subgrupo do esquema GSSK. Diante disso e dos resultados apresentados anteriormente na sub-seção VI-B, vê-se que o desempenho do esquema GSSK é praticamente idêntico ao obtido para detecção ótima $\mathrm{SM}$, porém com menor complexidade e equivalente à complexidade do esquema SSK. Novamente, esta baixa complexidade é atribuída ao fato dos símbolos na topologia GSSK não carregarem informação, diferentemente do que é feito na modulação espacial e na APM. Esta característica possibilita o uso de detectores não coerentes no receptor. Também notase que o desempenho GSSK é degradado com a diminuição do número de antenas transmissoras . Observa-se também que o ganho de desempenho do esquema GSSK em relação ao esquema V-BLAST é de $\approx 1 \mathrm{~dB}$ para uma taxa de erro de bit de $10^{-4}$. A ordem de diversidade deste sistema GSSK é igual a quatro, obtida pela inclinação assintótica ( $S N R \rightarrow \infty$ ) ou por $N_{r}$. Apesar de mais de uma antena transmissora ser ativada a cada instante, nota-se que este esquema não explora e não obtém ganho de diversidade existente na transmissão.

Figura 9 - Performance GSSK, SSK e V-BLAST com $N_{r}=4$ a 3 bits $/ \mathrm{s}$ em canal com desvanecimento Rayleigh Plano.

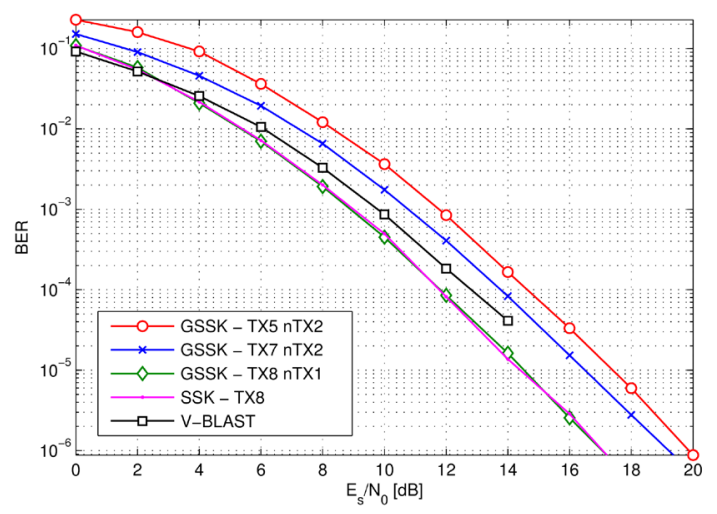

Fonte: Do Autor
Como foi constatado anteriormente, tanto para o esquema GSSK ou SSK quanto para o SM, o desempenho depende de estimativa correta do canal, pois a correta detecção está baseada na descorrelação entre os diversos canais gerados a partir das antenas transmissoras e receptoras.

\section{Conclusões}

Este trabalho apresentou uma análise comparada acerca da tecnologia de transmissão denominada modulação espacial e suas variações SSK e GSSK. Figuras de desempenho obtidas realçam o ganho de desempenho da técnica SM, que combina modulação espacial e de sinais, sobre o esquema clássico MIMO denominado V-BLAST. A complexidade computacional do esquema V-BLAST MMSE mostra-se superior à apresentada pelos esquemas SM apresentados, sendo que a análise é feita sob a mesma taxa de erro de bit para estes esquemas. A modulação GSSK também apresenta os mesmos ganhos obtidos por SSK, porém apresenta maior flexibilidade no projeto devido à possível combinação que pode ser feita com as antenas. Estes resultados revelam que esta técnica mostrase promissora para implementações de baixa complexidade em canais MIMO. Sugestões para análises futuras incluem a exploração da técnica de diversidade no transmissor para o esquema SM, combinando-se outras técnicas de transmissão e/ ou de diversidade difundidas na literatura com o esquema estudado neste trabalho.

\section{Referências}

ALAMOUTI, S. A simple transmit diversity technique for wireless communications. IEEE Journal on Selected Areas in Communications, New York, v. 16, n. 8, p. 1451-1458, Oct. 1998.

BIGLIERI, E.; CALDERBANK, R.; CONSTANTINIDES, A.; GOLDSMITH, A.; PAULRAJ, A.; POOR, H. V. MIMO Wireless Communications. New York: Cambridge University Press, 2007. 
BOHNKE, R.; WUBBEN, D.; KUHN, V.; KAMMEYER, K.-D. Reduced complexity mmse detection for blast architectures. In: GLOBAL TELECOMMUNICATIONS CONFERENCE, 2003, San Francisco. Proceedings... San Francisco: IEEE, 2003. v. 4. p. 2258-2262.

FOSCHINI, G. J. Layered space-time architecture for wireless communication in a fading environment when using multiple antennas. Bell Labs Technical Journal, Murray Hill, v. 1, n. 2, p. 41-59, 1996.

GOLDSMITH, A. Capacity limits of mimo channels. IEEE Journal on Selected Areas in Communication, New York, v. 21, n. 5, p. 684-702, Jun. 2003.

GOLUB, G.; LOAN, C. Matrix computations. Baltimore: Johns Hopkins University Press, 1996. (Johns Hopkins studies in the mathematical sciences).

HAYKIN, S. Communication Systems. 4. ed. New York: John Wiley \& Sons, 2001.

JEGANATHAN, J.; GHRAYEB, A.; SZCZECINSKI, L. Generalized space shift keying modulation for mimo channels. In: INTERNATIONAL SYMPOSIUM IN PERSONAL, INDOOR AND MOBILE RADIO COMMUNICATIONS, 19., 2008a, Cannes. Proceedings... Cannes: IEEE, 2008. p. 1-5.

. Spatial modulation: optimal detection and performance analysis. IEEE Communications Letters, New York, v. 12, n. 8, p. 545-547, 2008 b.

JEGANATHAN, J.; GHRAYEB, A.; SZCZECINSKI, L.; CERON, A. Space shift keying modulation for mimo channels. IEEE Transactions Wireless Communications, New York, v. 8, n. 7, p. 3692-3703, 2009.

LAUB, A. J. Matrix analysis for scientists and engineers. Philadelphia: SIAM, 2005.

MESLEH, R. Spatial modulation: a spatial multiplexing technique for efficient wireless data transmission. 2007. Dissertation (PhD) - Jacobs University, Bremen.

Spatial modulation. IEEE Transactions on Vehicular Technology, New York, v. 57, n. 4, p. 2228 2241, Jul. 2008.

MESLEH, R.; GANESAN, S.; HAAS, H. Impact of channel imperfections on spatial modulation ofdm. In: INTERNATIONAL SYMPOSIUM IN PERSONAL, INDOOR AND MOBILE RADIO COMMUNICATIONS, 18., 2007, Athens. Proceedings... Athens: IEEE, 2007. p. 1-5.

MESLEH, R.; HAAS, H.; AHN, C. W.; YUN, S. Spatial modulation - a new low complexity spectral efficiency enhancing technique. In: COMMUNICATIONS AND NETWORKING IN CHINA, 2006, Beijing. Proceedings... Beijing: ChinaCom, 2006. p. 1-5.
NAIDOO, N.; XU, H.; QUAZI, T. Spatial modulation: optimal detector asymptotic performance and multiplestage detection. IET Communications, Stevenage, v. 5, p. 1368-1376, Jul. 2011.

RALEIGH, G.; CIOFFI, J. Spatio-temporal coding for wireless communication. IEEE Transactions on Communications, New York, v. 46, n. 3, p. 357-366, Mar. 1998.

WOLNIANSKY, P.; FOSCHINI, G.; GOLDEN, G.; VALENZUELA, R. V-blast: an architecture for realizing very high data rates over the rich-scattering wireless channel. In: INTERNATIONAL SYMPOSIUM ON SIGNALS, SYSTEMS, AND ELECTRONICS, 1998, Pisa. Proceedings... Pisa: URSI, 1998. p. 295-300.

YOUNIS, A.; RENZO, M. D.; MESLEH, R.; HAAS, H. Sphere decoding for spatial modulation. In: IEEE INTERNATIONAL CONFERENCE COMMUNICATIONS, 2011, Kyoto. Proceedings... Kyoto: IEEE, 2011. p. 1-6.

Recebido em 19 Março 2012 - Received on March 19, 2012. Aceito em 4 Junho, 2012 - Accepted on June 4, 2012. 
